\title{
ANÁLISE ECONÔMICA DA PRODUÇÃO EM LAVOURAS TRANSGÊNICAS DE SOJA [GlycinemaxL. Merrill] EM FUNÇÃ̂ DE DOSES DE GLIFOSATO E MANGANÊS ${ }^{1}$
}

\author{
PEROZINI, Alexandre Caetano ${ }^{2}$ \\ ALMEIDA JÚNIOR, Joaquim Júlio ${ }^{3}$ \\ SMILJANIC, Katya Bonfim Ataides ${ }^{4}$ \\ MATOS, Francisco Solano Araújo ${ }^{5}$ \\ MIRANDA, Beatriz Campos ${ }^{6}$ \\ ARAÚJO, Charles ${ }^{7}$
}

RESUMO: O glifosato sal de isopropilamina de N - (fosfonometil) glicina é o herbicidas mais utilizados em sistemas de cultivo de produtos agrícolas geneticamente modificados, especialmente para a cultura da soja. Visando estudar os efeitos da aplicação de glifosato e manganês (Mn) em diferentes estádios de desenvolvimento sobre a viabilidade econômica, desenvolveu-se dois experimentos na Fazenda de Ensino e Pesquisa da UNESP-Ilha Solteira, localizada no município de Selvíria-MS. Os experimentos foram instalados utilizando-se a variedade de soja BRS Valiosa RR. O delineamento experimental utilizado foi blocos casualizados em arranjo fatorial. O produto utilizado para fornecer Mn contém como matéria prima sulfato de Mn quelatizado com EDTA. A fonte do N - (fosfonometil) glicina foi o Roundup Original com concentração de sal de Isopropilamina de glifosato $480 \mathrm{~g} \mathrm{~L}^{-1}\left(360 \mathrm{~g} \mathrm{~L}^{-1}\right)$. Os tratamentos: primeiro experimento com aplicação de glifosato nas doses de 0 ou $1440 \mathrm{~g}$ i.a. ha ${ }^{-1}$, parceladamente nos estádios V3 e V7 ou em dose única no estádio V7, na ausência ou presença de $350 \mathrm{~g} \mathrm{ha}^{-1} \mathrm{Mn}$, aplicado em dose única no estádio V5 ou parceladamente, com aplicações em V5 e V9. E no segundo experimento, a aplicação de glifosato, nas doses equivalente ácido de $720 \mathrm{~g}$ i.a. ha $^{-1}$ aplicado em V3, 1440 g i.a. ha ${ }^{-1}$ aplicados em V3 + V7, na ausência ou presença de $350 \mathrm{~g} \mathrm{ha}^{-1} \mathrm{Mn}$, aplicado no estádio V5. As pulverizações foliares dos tratamentos foram realizadas com pulverizador de barra de $5 \mathrm{~m}$, com bicos leque 110-02, espaçados de $50 \mathrm{~cm}$, acoplado ao trator, e calibrado para volume de aplicação de $200 \mathrm{~L} \mathrm{ha}^{-1}$ de calda. Diante dos resultados obtidos com os tratamentos utilizados foi possível identificar ganho na produtividade da cultura implantada, assim podemos concluir que o tratamento com maior viabilidade econômica foi verificado com a aplicação de $1440 \mathrm{~g}$ i.a. ha ${ }^{-1}$ de glifosato em estádios V3 e 0 g ha ${ }^{-1}$ de $\mathrm{Mn}_{\text {, }}$ obtendo uma margem de ganho bruto de valor de R $\$ 272,99 \mathrm{ha}^{-1}$.

Palavra-Chave: Herbicida. Nutriente. Estádios. Custos. Valor de produção.

SUMMARY: Glyphosate (N-[phosphonomethyl] glycine) is one of the most used herbicides in the systems of genetically modified agricultural product cultivation, especially for soybean. Studying the effects of glyphosate and manganese $(\mathrm{Mn})$ application in different development stages on economic viability, it was developed two experiments at the Teaching and Research Farm, UNESP-Ilha Solteira, located in Selvíria-MS. The experiments were conducted, using soybean BRS Valiosa RR. The used experimental design was randomized block design with 4 replications, factorial arrangement. The product used to provide $\mathrm{Mn}$ as raw material contains $\mathrm{Mn}$ sulfate chelated with EDTA. The source of $\mathrm{N}$-(phosphonomethyl) glycine was Roundup Original with concentration of isopropylamine salt of glyphosate $480 \mathrm{~g} \mathrm{~L}^{-1}\left(360 \mathrm{~g} \mathrm{~L}^{-1}\right)$. The treatments: first experiment with glyphosate application at doses of 0 or $1440 \mathrm{~g}$ i.a. ha ${ }^{-1}$ in installments V3 and V7 stages or in single dose V7 stage in the absence or presence of $350 \mathrm{~g}$ i.a. ha ${ }^{-1} \mathrm{Mn}$ applied in a single dose at V5 or in installments, with applications in V5 and V9. And in the second experiment, the glyphosate application in doses equivalent acid to $720 \mathrm{~g}$ i.a. $\mathrm{ha}^{-1}$ applied at V3, $1440 \mathrm{~g}$ i.a. $\mathrm{ha}^{-1}$ applied at V3 $+\mathrm{V} 7$, in the absence or presence of $350 \mathrm{~g}$ i.a. ha ${ }^{-1} \mathrm{Mn}$, applied at V5. The treatment foliar

\footnotetext{
${ }^{1}$ Parte da Tese de Doutorado do primeiro autor

${ }^{2}$ Engenheiro-Agrônomo, Prof. Titular, Doutor, Engenharia Rural e Fitotecnia. IFMT Campus São Vicente

${ }^{3}$ PÓS-DOUTORANDO em Sistema de Produção pela UC - UNIVERSIDADE DE COIMBRA. Professor Titular. UC - UNIVERSIDADE DE COIMBRA

${ }^{4}$ Engenheira-Agrônoma, Prof. Adjunta, Mestre, Bióloga, UniFIMES-GO. Centro Universitário de Mineiros.

${ }^{5}$ Engenheiro-Agrônomo, Prof. Adjunto, Mestre, Sanidade e Fitotecnia, UniFIMES-GO.

Centro Universitário de Mineiros.

${ }^{6}$ Acadêmica do curso de Engenharia Florestal. Centro Universitário de Mineiros

${ }^{7}$ IFMT Campus São Vicente. BR 364 Km 329. São Vicente da Serra. Santo Antônio do Leverger-MT. IFMT Campus São Vicente
} 
spray was always performed, with a $12 \mathrm{~m}$ long bar provided with 5 cone nozzles $110-02$, spaced $50 \mathrm{~cm}$, coupled to the tractor, and calibrated for application volume of $200 \mathrm{~L}$ ha-1 of syrup. Considering the results obtained with the treatments used, it was possible to identify a gain in the productivity of the implanted crop, so we can conclude that the treatment with greater economic viability was verified with the application of $1440 \mathrm{~g}^{\mathrm{ia} \mathrm{ha}} \mathrm{h}^{-1}$ glyphosate in stages V3 and $0 \mathrm{~g} \mathrm{ha}^{-1}$ of Mn, obtaining a gross profit margin of $\mathrm{R} \$ 272.99 \mathrm{ha}^{-1}$.

Keywords: Herbicide. Nutrient. Stadiums. Costs. Production value.

\section{INTRODUÇÃO}

Os Estados Unidos é o maior produtor mundial de soja, com uma produção de 119.518 milhões de toneladas em uma área plantada de 36.228 milhões de hectares com uma produtividade média de $3.299 \mathrm{~kg}$ $\mathrm{ha}^{-1}$ (USDA, 2018). Seguido pelo Brasil com uma produção de 116.996 milhões de toneladas em uma área plantada de 35.100 milhões de hectares e uma produtividade média de $3.333 \mathrm{~kg} \mathrm{ha}^{-1}$ (CONAB, 2018).

No Brasil, segundo dados da Companhia Nacional de Abastecimento - CONAB (2017), a soja atualmente tem uma produção anual a nível mundo de 351,311 milhões de toneladas, com uma área plantada de 120,958 milhões de hectares e produção a nível Brasil de 113.923 milhões de toneladas com uma área plantada de 33.890 milhões de hectares e uma produtividade média de $3.362 \mathrm{~kg} \mathrm{ha}^{-1}$, sendo o estado de Goiás responsável pela produção de 114,03 milhões de toneladas com produtividade média de $3.300 \mathrm{~kg} \mathrm{ha}^{-1}$.

A primeira planta transformada pela tecnologia do DNA recombinante foi desenvolvida no início da década de 80. Desde então, moléculas de DNA passaram a ser inserida em espécies de interesse, produzindo novas e desejadas particularidade (DULFIELD; GERMIDA, 2004). Esse é um processo mais rápido e preciso que o melhoramento convencional, pois permite a introdução de um único gene e modificação de uma característica especifica (SANTINONI, 2008).

No entanto, devido ao fato desses produtos possuírem materiais genéticos introduzidos, de forma artificial, de outros organismos vivos, ampliaram-se, também, as discussões a respeito dos potenciais riscos e benefícios decorrentes dessa moderna tecnologia empregada na agricultura (FIGUEIREDO, 2009). Dentre esses produtos, destaca-se a soja com resistência ao herbicida glifosato, cultura transgênica de maior exploração no mundo, responsável por $61 \%$ da área global cultivada com transgênicos, beneficiária de significativos avanços na pesquisa em biotecnologia que resultaram na criação de variedades de soja resistente ao glifosato, conhecidas como soja RR (Roundup Ready). Tal inovação proporcionou o uso deste herbicida na cultura com maior eficácia e amplo espectro de controle de plantas daninhas (KRUZE et al., 2000).

O glifosato é o mais comum herbicida em sistemas de cultivo (KRUZE et al., 2000; DUKE; POWLES, 2008). As principais ações deste herbicida são baseadas na inibição da enzima 5enolpyruvylshikimato 3-phosphate synthase (EPSPS) que resulta no reduzido biossíntese de aminoácidos aromáticos e alterações no metabolismo das proteínas. O glifosato causa também efeitos adversos sobre fotossíntese, metabolismo de carbono e translocação de sacarose nas plantas (GEIGER et al., 1999; RIBEIRO et al., 2008).

Na safra 2004/05 e 2005/06 foram avaliados adubos aplicados via foliar, na forma de fórmulas completas com vários elementos e/ou aminoácidos e produtos contendo um único nutriente (EMBRAPA, 2006). Entretanto, para o uso de aminoácidos, em alguns casos, o retorno econômico da aplicação dos nutrientes foi positivo, mas evidenciou sua dependência de altas produtividades e preços da soja favoráveis no momento da comercialização. Resultados de pesquisa obtidos têm demonstrado respostas 
significativas apenas para $\mathrm{Mn}$, cobalto (Co) e molibdênio (Mo), razão pela qual não existe a recomendação para adubação foliar com outros nutrientes (EMBRAPA, 2013).

Em condição de carência de Mn ocorre clorose entre as nervuras das folhas mais novas, as quais se tornam verde-pálido e passam para amarelo-pálido. Áreas necróticas marrons desenvolvem-se nas folhas à medida que a deficiência torna-se mais severa. Neste caso indica-se a aplicação de $350 \mathrm{~g} \mathrm{ha}^{-1} \mathrm{de}$ Mn diluídos em $200 \mathrm{~L}$ de água com 0,5\% de uréia. Para o Co e Mo sugere-se a aplicação via foliar de 12 a $30 \mathrm{~g} \mathrm{ha}^{-1}$ de Mo e 2 a $3 \mathrm{~g} \mathrm{ha}^{-1}$ de Co, entre os estádios $\mathrm{V}_{3}$ e $\mathrm{V}_{5}$. (EMBRAPA, 2006). Deve-se dar preferência para o fornecimento via foliar, uma vez que no tratamento de semente a aplicação de Co e Mo poderá reduzir a sobrevivência do Bradyrhizobium e, consequentemente, a nodulação e a fixação biológica do nitrogênio (STAUT, 2011). O Mn atua diretamente na fotossíntese e indiretamente na formação de carboidratos, assim, deficiências leves de Mn afetam a fotossíntese e diminuem o nível de carboidratos solúveis na planta (KIRKBY; ROMHELD, 2007). O Mn está envolvido em muitas funções bioquímicas, agindo principalmente como um activador de enzimas tais como desidrogenases, transferases, hidroxilases, e descarboxilases envolvidas na respiração (BARKER; PILBEAM, 2006).

Considerando que nesta cultura o glifosato e o uso do manganês têm um custo significativo na produção, o objetivo deste trabalho foi determinar a viabilidade econômica com a utilização de diferentes doses e épocas de aplicação destes insumos nos grãos de soja, no município de Selvíria-MS.

\section{MATERIAL E MÉTODO}

Foram conduzidos dois experimentos no ano agrícola 2012/13 no município de Selvíria-MS, cujas coordenadas geográficas aproximadas são $51^{\circ} 22^{\prime}$ de Longitude Oeste e $20^{\circ} 22^{\prime}$ Sul, e altitude de 335 m. Durante a realização dos experimentos na Figura 1 encontra-se os valores médios diários de temperatura máxima e mínima média do ar $\left({ }^{\circ} \mathrm{C}\right)$, umidade relativa do ar $(\%)$ e precipitação pluvial $(\mathrm{mm})$, nos meses de outubro a março de 2012, período entre a instalação do experimento e aplicações dos tratamentos, dados registrados no posto meteorológico da Fazenda de Ensino, Pesquisa e Extensão.

Figura 1. Valores mensais médios de umidade relativa (\%), temperaturas mínimas e máximas $\left({ }^{\circ} \mathrm{C}\right)$ e precipitação total $(\mathrm{mm})$, no período de condução dos experimentos 2012/13 na área experimental da Fazenda de Ensino, Pesquisa e Extensão Selvíria/MS, 2012/13.

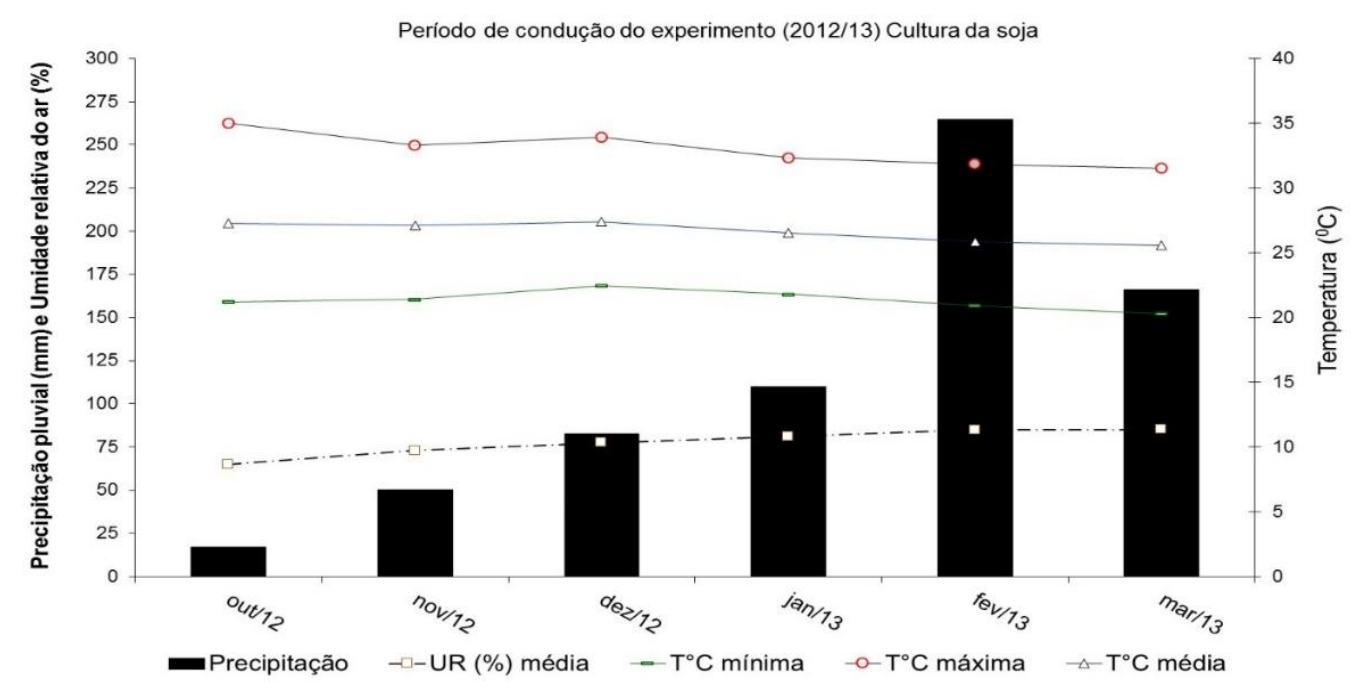

Fonte: Posto meteorológico da Fazenda de Ensino, Pesquisa e Extensão Universidade Estadual Paulista - Unesp (2013). 
O solo do local, classificado segundo o Sistema Brasileiro de Classificação de Solos (EMBRAPA, 2013), é um LATOSSOLO VERMELHO Distrófico típico argiloso a moderado mesoeutrófico álico caulinítico, mesoférrico muito profundo e fortemente ácido.

Na primeira quinzena de novembro de 2012, as plantas existentes na área experimental foram dessecadas com o uso do sal isopropilamina de $\mathrm{N}$-(phosphonomethyl) glicine na dose de $1440 \mathrm{~g}$ i.a. ha ${ }^{-1}$ (equivalente ácido) (4,0 $\mathrm{L} \mathrm{ha}^{-1}$ de glifosato) e então, sete dias após foi realizada a semeadura direta da soja (07/11/2012), utilizando-se a semeadora adubadora adequada para esta operação, em seguida fez-se a locação das parcelas experimentais.

No tratamento das sementes foi utilizado o produto a base de carboxim+thiram, na dose de $50+$ $50 \mathrm{~g}$ i.a. por $100 \mathrm{~kg}$ de sementes, respectivamente. O espaçamento adotado foi de 0,45 metros entre linhas com densidade de semeadura recomendada para a variedade, considerando um solo de média a alta fertilidade. A variedade de soja utilizada foi a BRS Valiosa RR, considerada de ciclo médio (maturação entre 123 a 130 dias) para a região e caracterizada por possuir hábito de crescimento determinado. Utilizou-se 16,2 sementes por metro de sulco com densidade de semeadura de $250 \mathrm{~kg}$ por ha de adubação básica da formulação 08-28-16 aplicado no sulco de semeadura.

O delineamento experimental utilizado foi em blocos casualizados em fatorial, com quatro repetições, e as parcelas foram constituídas de sete linhas com dez metros de comprimento. Área útil foi considerada três linhas centrais, desprezando-se um metro em cada extremidade. Nas Tabelas 1 e 2 , encontra-se os tratamentos avaliados nos experimentos. As pulverizações foliares foram realizadas sempre com temperatura inferior a $30^{\circ} \mathrm{C}$ e umidade relativa do ar acima de $60 \%$, no período da manhã dos tratamentos, realizadas com um pulverizador de barra de cinco metros de comprimento, provida com bicos leque 110-02, espaçados de cinquenta centímetros, acoplado ao trator, e calibrado para volume de aplicação de $200 \mathrm{~L} \mathrm{ha}^{-1}$ de calda. As aplicações do glifosato foram realizadas tanto nos Experimentos I e II de 30/11 a 15/12, respectivamente nos estádios V3 e V7.

Tabela 1. Tratamentos avaliados no Experimento I. Selvíria - MS, 2012/13.

\begin{tabular}{|c|c|c|c|c|}
\hline Tratamentos & $\begin{array}{l}\left.\text { glifosato (g i.a. } \text { ha }^{-1}\right) \\
\text { (equivalente ácido) } \\
\text { estádio da soja }\end{array}$ & $\begin{array}{c}\text { Mn }\left(\mathrm{g} \mathrm{ha}^{-1}\right) \text { e } \\
\text { estádio da soja }\end{array}$ & $\begin{array}{c}\text { Total glifosato } \\
\left.\text { (g i.a. ha }^{-1}\right) \\
\text { (equivalente ácido) }\end{array}$ & $\begin{array}{c}\text { Total Mn } \\
\left(\mathrm{g} \mathrm{ha}^{-1}\right)\end{array}$ \\
\hline 1 & 0 & 0 & 0 & 0 \\
\hline 2 & 0 & 350 (V5) & 0 & 350 \\
\hline 3 & 0 & 175+175 (V5+V9) & 0 & 350 \\
\hline 4 & $720+720(\mathrm{~V} 3+\mathrm{V} 7)$ & 0 & 1440 & 0 \\
\hline 5 & $720+720(\mathrm{~V} 3+\mathrm{V} 7)$ & 350 (V5) & 1440 & 350 \\
\hline 6 & $720+720(\mathrm{~V} 3+\mathrm{V} 7)$ & $175+175$ (V5+V9) & 1440 & 350 \\
\hline 7 & $1440(\mathrm{~V} 3)$ & 0 & 1440 & 0 \\
\hline 8 & $1440(\mathrm{~V} 3)$ & 350 (V5) & 1440 & 350 \\
\hline 9 & $1440(\mathrm{~V} 3)$ & $175+175$ (V5+V9) & 1440 & 350 \\
\hline
\end{tabular}


Tabela 2 - Tratamentos avaliados no Experimento II. Selvíria - MS, 2012/13.

\begin{tabular}{|c|c|c|c|c|}
\hline Tratamentos & $\begin{array}{l}\left.\text { glifosato (g i.a. } \text { ha }^{-1}\right) \\
\text { (equivalente ácido) e } \\
\text { estádio da soja }\end{array}$ & $\begin{array}{r}\text { Mn }\left(\mathrm{g} \mathrm{ha}^{-1}\right) \text { e } \\
\text { estádio da soja }\end{array}$ & $\begin{array}{c}\text { Total glifosato } \\
\left(\mathrm{g} \text { i.a. } \text { ha }^{-1}\right) \\
\text { (equivalente ácido) }\end{array}$ & $\begin{array}{c}\text { Total Mn } \\
\left(\mathrm{g} \mathrm{ha}^{-1}\right)\end{array}$ \\
\hline 1 & 0 & 0 & 0 & 0 \\
\hline 2 & 0 & $350(\mathrm{~V} 5)$ & 0 & 350 \\
\hline 3 & $720(\mathrm{~V} 3)$ & 0 & 720 & 0 \\
\hline 4 & $720(\mathrm{~V} 3)$ & $350(\mathrm{~V} 5)$ & 720 & 350 \\
\hline 5 & $1440(\mathrm{~V} 3)$ & 0 & 1440 & 0 \\
\hline 6 & $1440(\mathrm{~V} 3)$ & $350(\mathrm{~V} 5)$ & 1440 & 350 \\
\hline 7 & $720+720(\mathrm{~V} 3+\mathrm{V} 7)$ & 0 & 1440 & 0 \\
\hline 8 & $720+720(\mathrm{~V} 3+\mathrm{V} 7)$ & $350(\mathrm{~V} 5)$ & 1440 & 350 \\
\hline 9 & $1440(\mathrm{~V} 7)$ & 0 & 1440 & 0 \\
\hline 10 & 1440 (V7) & $350(\mathrm{~V} 5)$ & 1440 & 350 \\
\hline 11 & $720+1440(\mathrm{~V} 3+\mathrm{V} 7)$ & 0 & 2160 & 0 \\
\hline 12 & $720+1440(\mathrm{~V} 3+\mathrm{V} 7)$ & $350(\mathrm{~V} 5)$ & 2160 & 350 \\
\hline
\end{tabular}

Fonte: Elaboração do próprio autor, 2013.

A fonte utilizada foi o Roundup Original (nome comercial), cuja formulação corresponde a seguinte composição: Sal de Isopropilamina de N - (fosfonometil) glicina $480 \mathrm{~g} \mathrm{~L}^{-1}(48,0 \% \mathrm{~m} / \mathrm{v}$ ), Equivalente ácido de $\mathrm{N}$ - (fosfonometil) glicina (glifosato) $360 \mathrm{~g} \mathrm{~L}^{-1}(36,0 \% \mathrm{~m} / \mathrm{v})$, Ingredientes Inertes de $684 \mathrm{gL}^{-1}(68,4 \% \mathrm{~m} / \mathrm{v})$. As aplicações de $\mathrm{Mn}$ nos experimentos I e II ocorreram em 07 e 22/12, respectivamente nos estádios V5 e V9. A fonte utilizada apresentava as seguintes características: Produto líquido a base de sulfato de Mn quelatizado com EDTA, contendo 20\% de Mn e densidade de 1,65 g.L ${ }^{-1}$.

O manejo fitossanitário ao longo dos ciclos das plantas de soja foi efetuado de acordo com as recomendações técnica.

Para avaliar a análise econômica dos tratamentos aplicados nos Experimentos I e II, utilizou-se a técnica da orçamentação parcial, detalhada em Noronha (1987). A orçamentação parcial é utilizada para analisar decisões que envolvem modificações parciais na organização de uma atividade produtiva. Procura-se comparar os acréscimos de custos com os de benefícios da decisão. A melhor alternativa será aquela que oferecer maiores benefícios líquidos ou margens de ganho maiores. Esta técnica foi utilizada por outros autores em análises de experimentos (BINOTTI et al., 2010; TEIXEIRA FILHO et al., 2010; SILVA et al., 2013).

Para cada tratamento foram determinadas as receitas, os custos adicionais do uso do glifosato e do Mn e o valor da produção marginal. De acordo com a produção média de grãos de cada tratamento, calculou-se o acréscimo de produção proporcionado pelo uso do glifosato e Mn em relação à testemunha (sem glifosato e Mn). Segundo o IEA - Instituto de economia agrícola (2013), o preço de mercado em março de 2013 do glifosato era de $\mathrm{R} \$ 11,00 / \mathrm{L}$, e o preço do Mn de R \$35,00/ litro. O valor de produção marginal em cada tratamento foi obtido multiplicando-se a produtividade adicional pelo preço recebido pelos produtores de soja do Estado de São Paulo. Devido a região de estudo fazer divisa com o Estado de São Paulo (Selvíria-MS), utilizou-se os preços médios da soja pagos aos produtores praticados no mercado paulista em 2013 ou seja R 52,00/saca de $60 \mathrm{~kg}$ (IEA, 2013).

O custo da aplicação estimado em $\mathrm{R} \$ 90,00$ a hora máquina (aluguel), sendo o coeficiente técnico de $1,00 \mathrm{HM} \mathrm{ha}^{-1}$, ou seja, R $\$ 90,00 \mathrm{ha}^{-1}$.

A margem de ganho foi obtida pela subtração do valor da produção marginal com o custo marginal do uso do glifosato e/ou do Mn, para cada tratamento.

Nos experimentos, os dados foram submetidos à análise de variância (Teste F) e as médias dos 
tratamentos foram comparadas pelo teste de Tukey a 5\% de probabilidade, por meio do programa computacional SISVAR 5.0 (FERREIRA, 2003).

\section{RESULTADO E DISCUSSÃO}

A produtividade de grãos no Experimento I não foi significativa pelos tratamentos utilizados. Apesar de ter sido observado toxidade nas plantas de soja com a aplicação do glifosato, isso não proporcionou menor desenvolvimento das plantas e produtividade de grãos (Tabela 3). Em pesquisa realizada, também não observaram alteração na produtividade de grãos de soja, variedade Soy 8888-RR com aplicação de glifosato em uma única vez ou em aplicação sequencial, obtendo $2.910 \mathrm{~kg} \mathrm{ha}^{-1}$ no experimento conduzido por (FOLONI et al. 2005).

A média geral de produtividade de grãos dos tratamentos foram próximas da média nacional e superior a média obtida no Estado do Mato Grosso do Sul, ou seja, respectivamente 2880 e $2900 \mathrm{~kg} \mathrm{ha}^{-1}$ para ano agrícola de 2014 (CONAB, 2015). Verifica-se um desenvolvimento normal das plantas que receberam a aplicação de glifosato, em função das produtividades obtidas, podendo isso ser o reflexo das condições ambientais presentes durante o desenvolvimento do experimento, teor muito alto de Mn no solo ou até mesmo não efeito negativo do glifosato. Santos et al. (2007) citaram que pode ocorrer efeito variável do glifosato sobre o desenvolvimento da soja resultante a este herbicida, em função da formulação utilizada.

Tabela 3. Valores médios de produtividade de grãos de soja, em função de doses e épocas de aplicação de glifosato e Mn em soja no Experimento I. Selvíria-MS, 2013.

\begin{tabular}{lc}
\hline \multirow{2}{*}{ Tratamentos } & Produtividade \\
\cline { 2 - 3 } & $\left(\mathrm{kg} \mathrm{ha}^{-1}\right)$ \\
\hline Doses Glifosato $\left(\mathbf{g}^{\text {i.a. }} \mathbf{~ h a}^{-1}\right)$ & \\
\hline 0 & 2908 \\
$720+720(\mathrm{~V} 3+\mathrm{V} 7)$ & 2947 \\
$1440(\mathrm{~V} 3)$ & 2846 \\
\hline Doses Mn & \\
\hline 0 & 2884 \\
$175+175(\mathrm{~V} 5+\mathrm{V} 9)$ & 2844 \\
350 (V5) & 2972 \\
\hline F calculado (Fc) & \\
\hline Glifosato $(\mathrm{G})$ & $0,15^{\mathrm{ns}}$ \\
Mn & $0,24^{\mathrm{ns}}$ \\
GxMn & $0,50^{\mathrm{ns}}$ \\
\hline Média & $\mathbf{2 9 0 0}$ \\
C.V.\% & 15,72 \\
\hline
\end{tabular}

* Significativo $5 \%$ de probabilidade.

ns - não significativo.

A produtividade de grãos $\left(\mathrm{kg} \mathrm{ha}^{-1}\right)$ no Experimento II apresentou apenas diferença estatística significativa para os tratamentos com glifosato (Tabela 4), e não apresentou diferença para os tratamentos com Mn e na interação entre os tratamentos. Analisando-se, os tratamentos com glifosato, houve maiores produtividades de grãos de soja para os tratamentos com a dosagem de $1440 \mathrm{~g}$ i.a. ha ${ }^{-1}$ de glifosato no estádio V3 e para o tratamento com a dosagem de $1440 \mathrm{~g}$ i.a. ha ${ }^{-1}$ de glifosato no estádio V7 $(2.885 \mathrm{~kg} \mathrm{ha}$ ${ }^{1}, 2.847 \mathrm{~kg} \mathrm{ha}^{-1}$, respectivamente). Já o tratamento com a dosagem de $720+1440 \mathrm{~g}$ i.a. ha ${ }^{-1}$ de glifosato nos estádios V3 e V7 (2.257 $\left.\mathrm{kg} \mathrm{ha}^{-1}\right)$, teve a menor produtividade e com valores estatisticamente diferentes, 
mas não diferindo dos demais. Albrecht et al. (2009) caracterizaram diminuição significativa nas produtividades, demonstraram que altas doses de glifosato podem diminuir componentes de produção.

Tabela 4. Valores médios de produtividade de grãos de soja, em função de doses e épocas de aplicação de glifosato e Mn em soja no Experimento II. Selvíria-MS, 2013.

\begin{tabular}{lc}
\hline \hline \multirow{2}{*}{ Tratamentos } & Produtividade \\
\cline { 2 - 3 } & $\left.\mathbf{( k g ~ h a}^{-1}\right)$ \\
\hline Doses Glifosat $\left(\mathbf{g}\right.$ i.a. $\left.\mathbf{~ h a}^{-1}\right)$ & \\
\hline 0 & $2682 \mathrm{~b}$ \\
$720(\mathrm{~V} 3)$ & $2686 \mathrm{~b}$ \\
$720+720(\mathrm{~V} 3+\mathrm{V} 7)$ & $2530 \mathrm{~b}$ \\
$1440(\mathrm{~V} 3)$ & $2885 \mathrm{a}$ \\
$1440(\mathrm{~V} 7)$ & $2847 \mathrm{a}$ \\
$720+1440(\mathrm{~V} 3+\mathrm{V} 7)$ & $2257 \mathrm{~b}$ \\
\hline Doses Mn $\left(\mathbf{g ~ h a}^{-1}\right)$ & \\
\hline 0 & 2596 \\
$350(\mathrm{~V} 5)$ & 2699 \\
\hline $\mathrm{F}_{\text {Glifosato }}$ (G) & $3,72^{*}$ \\
$\mathrm{~F}_{\text {Mn }}$ & $1,13^{\text {ns }}$ \\
$\mathrm{F}_{\text {GxMn }}$ & $0,89^{\text {ns }}$ \\
\hline Média & 2648 \\
C.V.\% & 12,74 \\
\hline
\end{tabular}

* Significativo 5\% de probabilidade. ns - não significativo.

Segundo Zobiole et al. (2010), há evidências que sugerem que a produtividade da soja resistente a glifosato seja menor do que a das sojas convencionais. Muitos agricultores têm observado que tais produtividades, mesmo sob condições ótimas, não são tão elevadas, como esperado. É possível que a adição do gene que dá a resistência ao herbicida possa ter alterado outros processos fisiológicos. Zobiole et al. (2010), explicaram que as aplicações de glifosato podem retardar o metabolismo do Mn na planta bem como ter um efeito adverso nas populações de microrganismos do solo que são responsáveis pela redução do Mn em forma disponível para a planta; e que a adição de Mn suplementar, no período adequado, pode corrigir os sintomas de deficiência e resultar em maiores produtividades de soja. Porém, isto não foi observado no presente estudo.

Na tabela 5 constam os custos do insumo e sua aplicação $\left(\mathrm{R} \$ \mathrm{ha}^{-1}\right)$, a produtividade $\left(\mathrm{kg} \mathrm{ha}^{-1}\right)$, e na Tabela 6 o acréscimos de produtividade $\left(\mathrm{kg} \mathrm{ha}^{-1}\right)$ e do valor da produção ( $\mathrm{R} \$ / \mathrm{ha}$ ) para cada tratamento estudado, isto é, considerando doses de glifosato ( $\mathrm{g}$ i.a. ha $\left.{ }^{-1}\right)$, doses de $\mathrm{Mn}\left(\mathrm{g} \mathrm{ha}^{-1}\right)$ e estádio de aplicação nos Experimentos I e II. Observa-se que o custo do insumo total mais elevado foi no tratamento com as doses de 720+720 g i.a. ha ${ }^{-1}$ de glifosato nos estádios V3+V7 e com a dose $175+175$ g i.a. ha ${ }^{-1}$ Mn nos estádios V5 + V9 (Experimento I) obtendo o valor de R $\$ 441,10 \mathrm{ha}^{-1}$, seguido do tratamento com as doses de $720+1440$ g i.a. ha ${ }^{-1}$ de glifosato nos estádios V3+V7 e com a dose de 350 g i.a. ha ${ }^{-1} \mathrm{Mn}$ nos estádios V5 (Experimento II) obtendo o valor de R \$ 373,10 ha- (Tabela 5), com valor de total de produção inversamente proporcional ao acréscimo do valor da produção $(\mathrm{R} \$ / \mathrm{ha})$ que obteve um valor de $\mathrm{R} \$$ 251,16 (Tabela 6), assim inviabilizando completamente a aplicação de glifosato no estádio V3+V7 associado ao Mn no estádio V5.

Pode-se ressaltar que o tratamento com as doses de $720+720 \mathrm{~g}$ i. a. ha ${ }^{-1}$ de glifosato nos estádios V3+V7 e dose 350 g i.a. ha ${ }^{-1}$ de $\mathrm{Mn}$ nos experimentos I e II obteve um custo de insumo no total de $\mathrm{R} \$ 351,10 \mathrm{ha}^{-1}$ (Tabela 5). Já os outros tratamentos sem a utilização n, mas com o uso do glifosato 
na dose de 1440 g i.a. ha ${ }^{-1}$ no estádio V7 ficaram com custo de insumo de $\mathrm{R} \$ 134,00 \mathrm{ha}^{-1}$ (Tabela 5).

A produtividade de grãos de soja variou de $2240 \mathrm{~kg} \mathrm{ha}^{-1}$ para o tratamento de glifosato $720+1440$ g i.a. ha ${ }^{-1}$ em estádio V3 e V7 na dose de $350 \mathrm{~g} \mathrm{ha}^{-1}$ de Mn (Experimento II) a $3026 \mathrm{~kg} \mathrm{ha}^{-1}$ para o tratamento de $720+720 \mathrm{~g}$ i.a. ha ${ }^{-1}$ de glifosato em estádio $\mathrm{V} 3+\mathrm{V} 7$, na dose $350 \mathrm{~g} \mathrm{ha}^{-1} \mathrm{de} \mathrm{Mn}$ no Experimento I (Tabela 6). O acréscimo de produtividade foi maior para o tratamento $1440 \mathrm{~g}$ i.a. ha ${ }^{-1}$ de glifosato em estádio V3, na dose $0 \mathrm{~g} \mathrm{ha}^{-1} \mathrm{de} \mathrm{Mn}$ de $470\left(\mathrm{~kg} \mathrm{ha}^{-1}\right)$, isto é, um aumento de $18,56 \%$ acima da testemunha.

Tabela 5. -Custos do insumo e sua aplicação $\left(\mathrm{R} \$ \mathrm{ha}^{-1}\right)$ em função de doses de glifosato (g i.a. ha $\left.{ }^{-1}\right)$, doses de $\mathrm{Mn}\left(\mathrm{g} \mathrm{ha}^{-1}\right)$ e estádio de aplicação nos Experimentos I e II. Selvíria-MS, 2013.

\begin{tabular}{|c|c|c|c|c|c|c|}
\hline \multirow[b]{2}{*}{ Fontes } & \multicolumn{2}{|c|}{ Tratamentos } & \multirow[b]{2}{*}{$\begin{array}{l}\text { Produtividade } \\
\qquad\left(\mathrm{kg} \mathrm{ha}^{-1}\right)\end{array}$} & \multicolumn{3}{|c|}{ Custos de insumo e sua aplicação } \\
\hline & $\begin{array}{l}\text { Doses de } \\
\text { glifosato/ }\end{array}$ & $\begin{array}{l}\text { Doses de Mn/ } \\
\text { dio }\end{array}$ & & Glifosato & Mn & Total \\
\hline $\begin{array}{c}\text { Experimento } \\
\text { I }\end{array}$ & 0 & 0 & 2694 & ---- & ---- & ---- \\
\hline $\mathrm{Mn}$ & 0 & $350(\mathrm{~V} 5)$ & 3006 & 000,00 & 127,10 & 127,10 \\
\hline $\mathrm{Mn}$ & 0 & $175+175(\mathrm{~V} 5+\mathrm{V} 9)$ & 3024 & 000,00 & 217,10 & 217,10 \\
\hline G & $720+720(\mathrm{~V} 3+\mathrm{V} 7)$ & 0 & 3020 & 224,00 & 000,00 & 224,00 \\
\hline $\mathrm{G}+\mathrm{Mn}$ & $720+720(\mathrm{~V} 3+\mathrm{V} 7)$ & $350(\mathrm{~V} 5)$ & 3026 & 224,00 & 127,10 & 351,10 \\
\hline $\mathrm{G}+\mathrm{Mn}$ & $720+720(\mathrm{~V} 3+\mathrm{V} 7)$ & $175+175(\mathrm{~V} 5+\mathrm{V} 9)$ & 2797 & 224,00 & 217,10 & 441,10 \\
\hline $\mathrm{G}$ & $1440(\mathrm{~V} 3)$ & 0 & 2940 & 134,00 & 000,00 & 134,00 \\
\hline $\mathrm{G}+\mathrm{Mn}$ & $1440(\mathrm{~V} 3)$ & $350(\mathrm{~V} 5)$ & 2886 & 134,00 & 127,10 & 261,10 \\
\hline $\mathrm{G}+\mathrm{Mn}$ & $1440(\mathrm{~V} 3)$ & $175+175(\mathrm{~V} 5+\mathrm{V} 9)$ & 2713 & 134,00 & 217,10 & 351,10 \\
\hline $\begin{array}{c}\text { Experimento } \\
\text { II }\end{array}$ & 0 & 0 & 2529 & ---- & ---- & ---- \\
\hline $\mathrm{Mn}$ & 0 & $350(\mathrm{~V} 3)$ & 2834 & 0,00 & 127,10 & 127,10 \\
\hline $\mathrm{G}$ & $720(\mathrm{~V} 3)$ & 0 & 2509 & 112,00 & 000,00 & 112,00 \\
\hline $\mathrm{G}+\mathrm{Mn}$ & $720(\mathrm{~V} 3)$ & 350 (V5) & 2864 & 112,00 & 127,10 & 239,10 \\
\hline $\mathrm{G}$ & $1440(\mathrm{~V} 3)$ & 0 & 2999 & 134,00 & 000,00 & 134,00 \\
\hline $\mathrm{G}+\mathrm{Mn}$ & $1440(\mathrm{~V} 3)$ & $350(\mathrm{~V} 5)$ & 2771 & 134,00 & 127,10 & 261,10 \\
\hline $\mathrm{G}$ & $720+720(\mathrm{~V} 3+\mathrm{V} 7)$ & 0 & 2525 & 224,00 & 000,00 & 224,00 \\
\hline $\mathrm{G}+\mathrm{Mn}$ & $720+720(\mathrm{~V} 3+\mathrm{V} 7)$ & $350(\mathrm{~V} 5)$ & 2536 & 224,00 & 127,10 & 351,10 \\
\hline $\mathrm{G}$ & $1440(\mathrm{~V} 7)$ & 0 & 2740 & 134,00 & 000,00 & 134,00 \\
\hline $\mathrm{G}+\mathrm{Mn}$ & $1440(\mathrm{~V} 7)$ & $350(\mathrm{~V} 5)$ & 2955 & 134,00 & 127,10 & 261,10 \\
\hline G & $\begin{array}{c}720+1440 \\
(\mathrm{~V} 3+\mathrm{V} 7)\end{array}$ & 0 & 2275 & 246,00 & 000,00 & 246,00 \\
\hline $\mathrm{G}+\mathrm{Mn}$ & $\begin{array}{c}720+1440 \\
(\mathrm{~V} 3+\mathrm{V} 7)\end{array}$ & 350 (V5) & 2240 & 246,00 & 127,10 & 373,10 \\
\hline
\end{tabular}

O segundo maior acréscimo de produtividade $\left(426 \mathrm{~kg} \mathrm{ha}^{-1}\right)$ foi obtido com a aplicação de $1440 \mathrm{~g}$ i.a. ha ${ }^{-1}$ de glifosato em estádio V7, e dose de $350 \mathrm{~g} \mathrm{ha}^{-1}$ de Mn em estádio V5 (Tabela 6). Por outro lado os tratamentos com a aplicação de 720+1440 g i.a. ha ${ }^{-1}$ de glifosato em estádios V3 e V7 na dose $350 \mathrm{~g} \mathrm{ha}^{-1}$ de Mn em estádio V5 (- 251,16 kg ha ${ }^{-1}$ ) e 720+1440 g i.a. ha ${ }^{-1}$ de glifosato em estádios V3 e V7 na dose 0 $\mathrm{g} \mathrm{ha}^{-1} \mathrm{de} \mathrm{Mn}\left(-220,54 \mathrm{~kg} \mathrm{ha}^{-1}\right)$ apresentaram acréscimos negativos na produção (Experimento II). 
Tabela 6. Produtividade, acréscimos de produtividade $\left(\mathrm{kg} \mathrm{ha}^{-1}\right)$ e do valor da produção $(\mathrm{R} \$ / \mathrm{ha})$ em função de doses de glifosato (g i.a. ha $\left.{ }^{-1}\right)$, doses de $\mathrm{Mn}\left(\mathrm{g} \mathrm{ha}^{-1}\right)$ e estádio de aplicação nos Experimentos I e II. Selvíria-MS, 2013.

\begin{tabular}{|c|c|c|c|c|c|}
\hline \multirow{3}{*}{ Fontes } & \multicolumn{2}{|c|}{ Tratamentos } & \multirow{3}{*}{$\begin{array}{l}\text { Produtividade } \\
\qquad\left(\mathrm{kg} \mathrm{ha}^{-1}\right)\end{array}$} & \multicolumn{2}{|c|}{ Acréscimo } \\
\hline & Doses de glifosato/ & Doses de Mn/ & & $\begin{array}{c}\text { Produtividade } \\
\left(\mathrm{kg} \mathrm{ha}^{-1}\right)\end{array}$ & $\begin{array}{c}\text { Valor da } \\
\text { Produção }(\mathbf{R} \$)\end{array}$ \\
\hline & \multicolumn{2}{|c|}{ estádio } & & & 2013 \\
\hline Experimento I & 0 & 0 & 2694 & ---- & ---- \\
\hline $\mathrm{Mn}$ & 0 & 350 (V5) & 3006 & 311 & 269,70 \\
\hline $\mathrm{Mn}$ & 0 & $175+175(\mathrm{~V} 5+\mathrm{V} 9)$ & 3024 & 330 & 286,02 \\
\hline G & $720+720(\mathrm{~V} 3+\mathrm{V} 7)$ & 0 & 3020 & 326 & 282,44 \\
\hline $\mathrm{G}+\mathrm{Mn}$ & $720+720(\mathrm{~V} 3+\mathrm{V} 7)$ & 350 (V5) & 3026 & 332 & 287,64 \\
\hline $\mathrm{G}+\mathrm{Mn}$ & $720+720(\mathrm{~V} 3+\mathrm{V} 7)$ & $175+175(\mathrm{~V} 5+\mathrm{V} 9)$ & 2797 & 103 & 89,30 \\
\hline G & $1440(\mathrm{~V} 3)$ & 0 & 2940 & 246 & 213,32 \\
\hline $\mathrm{G}+\mathrm{Mn}$ & $1440(\mathrm{~V} 3)$ & 350 (V5) & 2886 & 191 & 165,85 \\
\hline $\mathrm{G}+\mathrm{Mn}$ & $1440(\mathrm{~V} 3)$ & $175+175(\mathrm{~V} 5+\mathrm{V} 9)$ & 2713 & 19 & 16,23 \\
\hline $\begin{array}{c}\text { Experimento } \\
\text { II }\end{array}$ & 0 & 0 & 2529 & ---- & ---- \\
\hline $\mathrm{Mn}$ & 0 & $350(\mathrm{~V} 3)$ & 2834 & 305 & 264,05 \\
\hline G & $720(V 3)$ & 0 & 2509 & -21 & $-17,81$ \\
\hline $\mathrm{G}+\mathrm{Mn}$ & $720(\mathrm{~V} 3)$ & 350 (V5) & 2864 & 334 & 289,52 \\
\hline G & $1440(\mathrm{~V} 3)$ & 0 & 2999 & 470 & 406,99 \\
\hline $\mathrm{G}+\mathrm{Mn}$ & $1440(\mathrm{~V} 3)$ & $350(\mathrm{~V} 5)$ & 2771 & 241 & 209,15 \\
\hline G & $720+720(\mathrm{~V} 3+\mathrm{V} 7)$ & 0 & 2525 & -5 & $-3,92$ \\
\hline $\mathrm{G}+\mathrm{Mn}$ & $720+720(\mathrm{~V} 3+\mathrm{V} 7)$ & 350 (V5) & 2536 & 7 & 5,67 \\
\hline G & $1440(\mathrm{~V} 7)$ & 0 & 2740 & 210 & 182,31 \\
\hline $\mathrm{G}+\mathrm{Mn}$ & $1440(\mathrm{~V} 7)$ & $350(\mathrm{~V} 5)$ & 2955 & 426 & 368,89 \\
\hline G & $720+1440(\mathrm{~V} 3+\mathrm{V} 7)$ & 0 & 2275 & -254 & $-220,54$ \\
\hline $\mathrm{G}+\mathrm{Mn}$ & $720+1440(\mathrm{~V} 3+\mathrm{V} 7)$ & 350 (V5) & 2240 & -290 & $-251,16$ \\
\hline
\end{tabular}

$* \mathrm{G}=$ Glifosato, Mn = Manganês

De forma geral os tratamentos com a aplicação de $720+720$ g i.a. ha ${ }^{-1}$ de glifosato em estádios V3 e V7 na dose $0 \mathrm{~g} \mathrm{ha}^{-1}$ de $\mathrm{Mn}\left(-5 \mathrm{~kg} \mathrm{ha}^{-1}\right)$ e $720+720 \mathrm{~g}^{\text {i.a. }}$ ha ${ }^{-1}$ de glifosato em estádios V3 e V7 na dose $350 \mathrm{~g} \mathrm{ha}^{-1}$ de Mn em estádio V5 $\left(7 \mathrm{~kg} \mathrm{ha}^{-1}\right)$ apresentaram os acréscimos na produtividade em níveis intermediários (Tabela 6). Com relação ao acréscimo no valor da produção, esse foi negativo para quatro dos tratamentos estudados, os maiores valores foram obtidos para os tratamentos de $1440 \mathrm{~g}$ i.a. ha ${ }^{-1}$ de glifosato em estádio V3, na dose $0 \mathrm{~g} \mathrm{ha}^{-1}$ de $\mathrm{Mn} \mathrm{R} \$ 406,99 \mathrm{ha}^{-1}$ e para $1440 \mathrm{~g}$ i.a. ha ${ }^{-1}$ de glifosato em estádio V7, na dose $350 \mathrm{~g} \mathrm{ha}^{-1}$ de Mn em estádio V5 com valor de R $\$ 368,89 \mathrm{ha}^{-1}$.

$\mathrm{O}$ tratamento de $720 \mathrm{~g}$ i. a. ha ${ }^{-1}$ de glifosato no estádio V3 e a dose $0 \mathrm{~g} \mathrm{ha}^{-1}$ de Mn do Experimento II obteve o menor custo de insumo total $\mathrm{R} \$ 112,00 \mathrm{ha}^{-1}$ mas também se mostrou ineficaz no tocante ao custo de produção total com valor de $\mathrm{R} \$-17,81 \mathrm{ha}^{-1}$ (Tabela 6) demonstrando a inviabilidade do tratamento.

Albrecht et al., (2008; 2009) relataram efeitos negativos do glifosato sobre a produtividade da soja, quando aplicado de forma sequencial detectaram decréscimo na sanidade das sementes com o uso de doses comerciais de glifosato; caracterizaram diminuição significativa nos componentes de produção. Sendo assim a aplicação de 720+1440 g i.a. ha ${ }^{-1}$ de glifosato em estádios V3 e V7 e $0 \mathrm{~g} \mathrm{ha}^{-1}$ de Mn (2275 $\mathrm{kg} \mathrm{ha}^{-1}$ ) e $720+1440 \mathrm{~g}$ i.a. ha ${ }^{-1}$ de glifosato em estádios V3 e V7 na dose $350 \mathrm{~g} \mathrm{ha}^{-1} \mathrm{de} \mathrm{Mn} \mathrm{em} \mathrm{estádio} \mathrm{V5}$ 
(2240 kg ha ${ }^{-1}$ ) apresentaram as menores produtividades caracterizando diminuição nos componentes de produção quando comparados com a testemunha (2529 $\mathrm{kg} \mathrm{ha}^{-1}$ ) no Experimento II (Tabela 6).

Resultados de pesquisa obtidos têm demonstrado respostas significativas apenas para Mn, Co e Mo, razão pela qual existe ser poucas recomendações para adubação foliar com outros nutrientes. Em condição de carência de Mn ocorre clorose entre as nervuras das folhas mais novas, as quais se tornam verde-pálido e passam para amarelo-pálido. Áreas necróticas marrons desenvolvem-se nas folhas à medida que a deficiência torna-se mais severa. Neste caso indica-se a aplicação de $350 \mathrm{~g} \mathrm{ha}^{-1} \mathrm{de} \mathrm{Mn}$ diluídos em $200 \mathrm{~L}$ de água com $0,5 \%$ de ureia (EMBRAPA, 2006). Neste contexto, a aplicação de $350 \mathrm{~g} \mathrm{ha}^{-1}$ de $\mathrm{Mn}$ utilizada isoladamente em estádio $\mathrm{V} 3$, proporcionou produtividade superior $\left(3006 \mathrm{~kg} \mathrm{ha}^{-1}\right.$ ) quando comparada ao tratamento $0 \mathrm{~g} \mathrm{ha}^{-1}$ de Mn (Tabela 6).

Na Tabela 6 (Experimento II) estão apresentados os acréscimos do valor da produção, do custo total dos insumos e da margem de ganho bruto para cada tratamento estudado, isto é, considerando doses de glifosato ( $\mathrm{g}$ i.a. ha ${ }^{-1}$ ), doses de $\mathrm{Mn}\left(\mathrm{g} \mathrm{ha}^{-1}\right)$ para diferentes estádios de aplicação. Os acréscimos no valor da produção, foram negativos para quatro dos tratamentos estudados, os maiores valores foram obtidos para os tratamentos de $1440 \mathrm{~g}$ i.a. ha ${ }^{-1}$ de glifosato em estádio V3, na dose $0 \mathrm{~g} \mathrm{ha}^{-1}$ de Mn R $\$ 406,99 \mathrm{ha}^{-1} \mathrm{e}$ para $1440 \mathrm{~g}$ i.a. $\mathrm{ha}^{-1}$ de glifosato em estádio V7, na dose $350 \mathrm{~g} \mathrm{ha}^{-1} \mathrm{de}$ Mn em estádio V5 com valor de R\$ 368,89 ha $^{-1}$ (Tabela 7).

Tabela 7. Acréscimos em $\mathrm{R} \$$ por ha do valor da produção, dos custos total dos insumos, da margem de ganho bruto em função de doses de glifosato $\left(\mathrm{g}\right.$ i.a. ha $\left.{ }^{-1}\right)$, doses de $\mathrm{Mn}\left(\mathrm{g} \mathrm{ha}^{-1}\right)$ e estádio de aplicação nos Experimentos I e II. Selvíria-MS, 2013.

\begin{tabular}{|c|c|c|c|c|c|}
\hline \multirow{3}{*}{ Fontes } & \multicolumn{2}{|c|}{ Tratamentos } & \multirow{3}{*}{$\begin{array}{c}\text { Acréscimo } \\
\text { Valor da } \\
\text { Produção (R\$) } \\
2013 \\
\end{array}$} & \multirow{2}{*}{$\begin{array}{l}\text { Custo total } \\
\text { dos insumos }\end{array}$} & \multirow{2}{*}{$\begin{array}{c}\text { Margem de } \\
\text { ganho bruto } \\
\text { (R\$/ha) }\end{array}$} \\
\hline & Doses de glifosato/ & Doses de Mn/ & & & \\
\hline & \multicolumn{2}{|c|}{ estádio } & & & \\
\hline Experimento I & 0 & 0 & --- & ---- & --- \\
\hline $\mathrm{Mn}$ & 0 & $350(\mathrm{~V} 5)$ & 269,70 & 127,10 & 142,60 \\
\hline $\mathrm{Mn}$ & 0 & 175+175 (V5+V9) & 286,02 & 217,10 & 68,92 \\
\hline $\mathrm{G}$ & $720+720(\mathrm{~V} 3+\mathrm{V} 7)$ & 0 & 282,44 & 224,00 & 58,44 \\
\hline $\mathrm{G}+\mathrm{Mn}$ & $720+720(\mathrm{~V} 3+\mathrm{V} 7)$ & $350(\mathrm{~V} 5)$ & 287,64 & 351,10 & $-63,46$ \\
\hline $\mathrm{G}+\mathrm{Mn}$ & $720+720(\mathrm{~V} 3+\mathrm{V} 7)$ & 175+175 (V5+V9) & 89,30 & 441,10 & $-351,80$ \\
\hline $\mathrm{G}$ & $1440(V 3)$ & 0 & 213,32 & 134,00 & 79,32 \\
\hline $\mathrm{G}+\mathrm{Mn}$ & $1440(\mathrm{~V} 3)$ & $350(\mathrm{~V} 5)$ & 165,85 & 261,10 & $-95,25$ \\
\hline $\mathrm{G}+\mathrm{Mn}$ & $1440(\mathrm{~V} 3)$ & 175+175 (V5+V9) & 16,23 & 351,10 & $-334,87$ \\
\hline Experimento II & 0 & 0 & ---- & $-\overline{---}$ & $-\overline{---}$ \\
\hline $\mathrm{Mn}$ & 0 & $350(\mathrm{~V} 3)$ & 264,05 & 127,10 & 136,95 \\
\hline $\mathrm{G}$ & $720(\mathrm{~V} 3)$ & 0 & $-17,81$ & 112,00 & $-129,81$ \\
\hline $\mathrm{G}+\mathrm{Mn}$ & $720(\mathrm{~V} 3)$ & $350(\mathrm{~V} 5)$ & 289,52 & 239,10 & 50,42 \\
\hline $\mathrm{G}$ & $1440(\mathrm{~V} 3)$ & 0 & 406,99 & 134,00 & 272,99 \\
\hline $\mathrm{G}+\mathrm{Mn}$ & $1440(\mathrm{~V} 3)$ & 350 (V5) & 209,15 & 261,10 & $-51,95$ \\
\hline $\mathrm{G}$ & $720+720(\mathrm{~V} 3+\mathrm{V} 7)$ & 0 & $-3,92$ & 224,00 & $-227,92$ \\
\hline $\mathrm{G}+\mathrm{Mn}$ & $720+720(\mathrm{~V} 3+\mathrm{V} 7)$ & $350(\mathrm{~V} 5)$ & 5,67 & 351,10 & $-345,43$ \\
\hline $\mathrm{G}$ & $1440(\mathrm{~V} 7)$ & 0 & 182,31 & 134,00 & 48,31 \\
\hline $\mathrm{G}+\mathrm{Mn}$ & $1440(\mathrm{~V} 7)$ & $350(\mathrm{~V} 5)$ & 368,89 & 261,10 & 107,79 \\
\hline $\mathrm{G}$ & $720+1440(\mathrm{~V} 3+\mathrm{V} 7)$ & 0 & $-220,54$ & 246,00 & $-466,54$ \\
\hline $\mathrm{G}+\mathrm{Mn}$ & $720+1440(\mathrm{~V} 3+\mathrm{V} 7)$ & $350(\mathrm{~V} 5)$ & $-251,16$ & 373,10 & $-624,26$ \\
\hline
\end{tabular}

${ }^{*} \mathrm{G}=$ Glifosato, $\mathrm{Mn}=$ Manganês 
Analisando de forma geral, à margem de ganho bruto, o tratamento com dose de glifosato de 720+1440 nos estádios V3+V7 na dose de 350 g i.a. ha ${ }^{-1}$ de Mn no estádio V5 este obteve valor de R\$ $624,26 \mathrm{ha}^{-1}$ (Tabela 7), sendo este o tratamento com a menor resposta lucrativa, também pode-se observar que o mesmo tratamento na dose de 720+1440 g i.a. ha ${ }^{-1}$ de glifosato nos estádios V3+V7 e dose $0 \mathrm{~g}$ i. a. $\mathrm{ha}^{-1}$ de Mn foi o segundo com menor ganho bruto de $\mathrm{R} \$-466,54 \mathrm{ha}^{-1}$. Sendo que a maior resposta lucrativa foi obtido para os tratamentos de $1440 \mathrm{~g}$ i.a. ha ${ }^{-1}$ de glifosato em estádio V3, na dose $0 \mathrm{~g} \mathrm{ha}^{-1} \mathrm{de}$ Mn com a margem de ganho bruto de $\mathrm{R} \$ 272,99 \mathrm{ha}^{-1}$.

\section{CONCLUSÃO}

O tratamento mais viável economicamente foi verificado com a aplicação de 1440 g i.a. ha ${ }^{-1}$ de glifosato em estádios V3 e $0 \mathrm{~g} \mathrm{ha}^{-1}$ de $\mathrm{Mn}$, obtendo uma margem de ganho bruto de valor de $\mathrm{R} \$ 272,99$ ha 1 .

\section{REFERÊNCIAS}

BARKER, V. A. ; PILBEAM, J. D. Handbook of plant nutrition. Boca Raton: CRC, 2006. 662 p. (Books in soils, plants, and the environment, 117).

BINOTTI, F. F. S.et al. Fontes e doses de nitrogênio em cobertura no feijoeiro de inverno irrigado no sistema plantio direto. Bioscience Journal, Uberlândia, v. 26, n. 5, p. 770-778, 2010.

CONAB-COMPANHIA NACIONAL DE ABASTECIMENTO. Acompanhamento da safra de grãos 2017/2018. Disponível em: <http://www.conab.gov.br/conteudos.php?a=1253\&t=2>. Acesso: 13 set. 2018.

DUKE, S.; POWLES, S. B. Glyphosate: a once-in-a-century herbicide. Pest Management Science, Sussex, v. 64, p. 319-325, 2008.

DUNFIELD, K. E.; GERMIDA, J. J. Impacto f GM crops on microbial biodiversity. Journal of Envioronmental Quality, Madison, v. 33, n. 3, p. 806-815, 2004.

EMBRAPA - Empresa Brasileira de Pesquisa Agropecuária. Sistema Brasileiro de Classificação de Solos. Brasília, 3.ed.. 2013. 353 p. ISBN 978-85-7035-198-2

EMBRAPA - EMPRESA BRASILEIRA DE PESQUISA AGROPECUÁRIA. Tecnologia de produção de soja - Região Central do Brasil - 2006. Londrina: Embrapa Soja, Embrapa Cerrados, Embrapa Agropecuária Oeste, 2006. 225 p. (Embrapa Soja. Sistema de Produção, 9).

FERREIRA, D. SISVAR software: versão 5.0. Lavras: DEX/UFLA, 2003.

FIGUEIREDO, L. A. Nutrição nitrogenada $\left({ }^{15} \mathrm{~N}\right)$ em soja convencional e transgênica sob aplicação do herbicida glifosato. 2009. 82 f. Dissertação (Mestrado em Energia Nuclear na Agricultura) - Escola Superior de Agricultura “Luiz de Queiroz”, Universidade de São Paulo, Piracicaba, 2009.

FOLONI, L. L.et al. Aplicação de glifosato em pós-emergênica, em soja transgênica cultivada no cerrado. Revista Brasileira de Herbicidas, Brasília, DF, v. 4, n. 3, p. 47-58, 2005.

GEIGER, D. R.; SHIEHS, W. J.; FUCHS, M. A. Causes of self-limited translocation of glyphosate in Beta vulgaris plants. Pesticide Biochemistry and Physiology, San Diego, v. 64, p. 124-133, 1999. 
IEA - Instituto de Economia Agrícola. Preços. Disponível em:

<http://www.iea.sp.gov.br/out/banco/menu.phppreços>. Acesso em: 10 ago. 2013.

KIRKBY, E. A.; RÖMHELD, V. Micronutrientes na fisiologia de plantas: funções, absorção e mobilidade. Encarte técnico. Informações Agronômicas, Piracicaba, n. 118, p. 12-15, 2007.

KRUZE, N. D.; TREZZI, M. M.; VIDAL, R. A. Herbicidas inibidores da EPSPs: revisão de literatura. Revista Brasileira de Herbicidas, Brasília, DF, v. 1, n. 2, p. 139-146, 2000.

MUNOZ, C. C.; PALMEIRA, E. M. A. Desafios de logística nas exportações brasileiras do complexo agronegocial da soja: 2006. Disponível em: 〈http://www.eumed.net/cursecon/ecolat/br/06/ccm.pdf〉. Acesso em: 4 ago. 2011.

NORONHA, J. F. Projetos agropecuários: administração financeira, orçamento e avaliação econômica. 2. ed. São Paulo: Atlas, 1987. 269 p.

RIBEIRO, D. N.et al. Rapid assays for detection of glyphosate-resistant Lolium spp. Journal of Plant Diseases and Protection, Sonderheft, v. 21, p. 95-100, 2008.

SANTINONI, I. A. Avaliação do impacto ambiental da soja transgênica resistente ao glifosato sobre alguns grupos funcionais de microorganismos do solo. 2008. 67 f. Dissertação (Mestrado em Microbiologia) - Universidade Estadual de Londrina, Londrina, 2008.

SANTOS, J. B. et al. Avaliação de formulações de Glyphosate sobre soja Roundup Ready. Planta Daninha, Rio de Janeiro, v. 25, n. 1, p. 165-171, 2007

SILVA. J. da et al. Análise econômica do efeito hormese de glifosato em feijoeiro. Enciclopédia Biosfera, Goiânia, v. 9, n. 16, p. 182-194, 2013.

STAUT, L. A. Adubação foliar com nutrientes na cultura da soja. Disponível em: <http://www.agronline.com.br/artigos/artigo.php?id=413>. Acesso em: 3 ago. 2011.

TEIXEIRA FILHO, M. C. M.et al. Análise econômica da adubação nitrogenada em trigo irrigado sob plantio direto no cerrado. Revista Ceres, Viçosa, v. 57, n. 4, p. 446-453, 2010.

USDA-Serviço de Pesquisa Agrícola do Departamento de Agricultura dos Estados Unidos. Boletim Técnico. Disponível em; https://www.noticiasagricolas.com.br/noticias/usda/. Acesso em 13 set. 2018.

ZOBIOLE, L. H. S. et al. Glyphosate Affects Seed Composition in Glyphosate-Resistant Soybean. Journal of Agricultural and a Food Chemistry, Easton, v. 58, p. 4517-4522, 2010. 